\title{
Environmental assessment of drinking water transport and distribution network use phase for small to medium-sized municipalities in Spain
}

David Sanjuan-Delmás ${ }^{\mathrm{a}}$; Anna Petit-Boix ; Carles M. Gasol ${ }^{\mathrm{b}}$; Ramon Farreny ${ }^{\mathrm{b}}$; Gara Villalba ${ }^{\mathrm{a}, \mathrm{c}}$; María Eugenia Suárez-Ojeda ${ }^{\mathrm{d}}$; Xavier Gabarrell, ${ }^{\mathrm{a}, \mathrm{e}}$; Alejandro Josa ${ }^{\mathrm{f}, \mathrm{g}}$; Joan Rieradevalla,c

asostenipra, Institute of Environmental Sciences and Technology (ICTA), Universitat Autònoma de Barcelona (UAB), Campus UAB, 08193 Bellaterra, Barcelona, Spain. 2014 SGR 1412.

${ }^{b}$ Inèdit innovació. Spin off of UAB Research park. Cabrils Road Km 2(IRTA) 08348, Cabrils, Barcelona, Spain.

'Department of Chemical Engineering, Universitat Autònoma de Barcelona (UAB), Campus UAB, 08193 Bellaterra, Barcelona, Spain.

dGENOCOV. Department of Chemical Engineering, School of Engineering, Universitat Autònoma de Barcelona, 08193 Bellaterra, Barcelona, Spain.

eDepartment of Chemical Engineering, (Catalan Biotechnology Reference Network XRB-), Universitat Autònoma de Barcelona (UAB), Campus UAB, 08193 Bellaterra, Barcelona, Spain.

fDepartment of Geotechnical Engineering and Geosciences, School of Civil Engineering, Technical University of Catalonia - Barcelona Tech, Campus Nord, C/Jordi Girona 1-3, Building D2, 08034 Barcelona, Catalonia, Spain

${ }^{9}$ Institute of Sustainability (IS.UPC), Technical University of Catalonia-Barcelona Tech, UPC, Campus Nord, Building VX. PI. Eusebi Güell, 6, 08034 Barcelona, Catalonia, Spain

Corresponding author: David Sanjuan-Delmás, Sostenipra, Institute of Environmental Sciences and Technology (ICTA), Universitat Autònoma de Barcelona (UAB), Campus UAB, 08193 Bellaterra, Barcelona, Spain. 2014 SGR 1412. Phone number: (34)935813760 Email: david.sanjuan@uab.cat

Word count: 7,218 


\begin{abstract}
Previous studies assessing the environmental impacts of drinking water supply networks have considered a bottom-up approach, analysing single case studies. This paper presents a top-down approach for the assessment of the operational phase of a water supply network. A representative sample of 50 cities was statistically analysed to find relations between different variables regarding electricity and water consumption linked with the environmental impacts of the network. The results show that some of the variables are clearly related to the relative energy consumption of the network. Such is the case for population size, where small municipalities have up to 14 times higher relative electricity consumption compared with medium-sized municipalities (1.15E-2 as opposed to $8.3 \mathrm{E}-4 \mathrm{kWh} / \mathrm{m} 3$ registered water $\cdot \mathrm{km}$ of network) due to casespecific factors such as a strong gradient between a water tank and the consumption point. Similarly, the cases showing low population density exhibit 7 times higher relative electricity consumption because of the longer distances that must be covered and the correlation between population density and size. The values found for greenhouse gas (GHG) emissions derived from the energy consumption are consistent with results from previous studies: on average, $5.53 \mathrm{~kg}$ of $\mathrm{CO}_{2}$ eq. emissions/inhabitant.year are released, but the variability is very high, ranging from 0.005 to $67.8 \mathrm{~kg}$ of $\mathrm{CO}_{2}$ eq. emissions/inhabitant-year. No clearly significant correlations were found between the relative water demand and variables such as seasonality or income per capita, which might indicate that water consumption depends on individual decisions of the population rather than on the variables assessed. Models for the estimation of water demand, length of network and electricity consumption were defined. However, the modelling of electricity consumption presented more difficulties because of its high variability. A protocol for data collection should be defined and implemented in the future to enable the analysis of more high quality case studies and for the definition of more accurate and reliable models.
\end{abstract}

Keywords: urban water cycle, energy, water supply, water pipeline, sustainability, $\mathrm{CO}_{2}$ emissions 


\section{Previous literature}

\subsection{Urban water cycle}

The supply of drinking water is a basic need for the development of towns and villages. However, the water consumption in populated areas alters water fluxes, thus impacting ecosystems and resulting in degradation (UNESCO, 2006). Studies focused on urban metabolism, which is the sum of technical and socio-economic processes in cities, consider the water cycle as one of the main fluxes within cities (Kennedy, 2011).

The consumption of water generates important environmental impacts because of the abstraction, treatment and transport of water (Vince et al., 2008; Racoviceanu et al., 2007). The urban water cycle (UWC) comprises different stages, from water abstraction to its discharge to environment after use. First, water is extracted from the surface or groundwater and is transported to the drinking water treatment plant (DWTP), where it is treated to reach the necessary quality to be suitable for drinking. Then, it is transported through the principal network (transport) and the secondary network (distribution) to the consumption points around the urban area. Once in the urban area, water is used for drinking and domestic uses in houses and buildings as well as for a wide range of activities (e.g., industry, services). After its use, the water is collected and transported to the waste water treatment plant, where it is depurated to the necessary quality to be released back into nature (Figure 1) (UNESCO, 2006). Nonetheless, this schema can vary depending on the specific case.

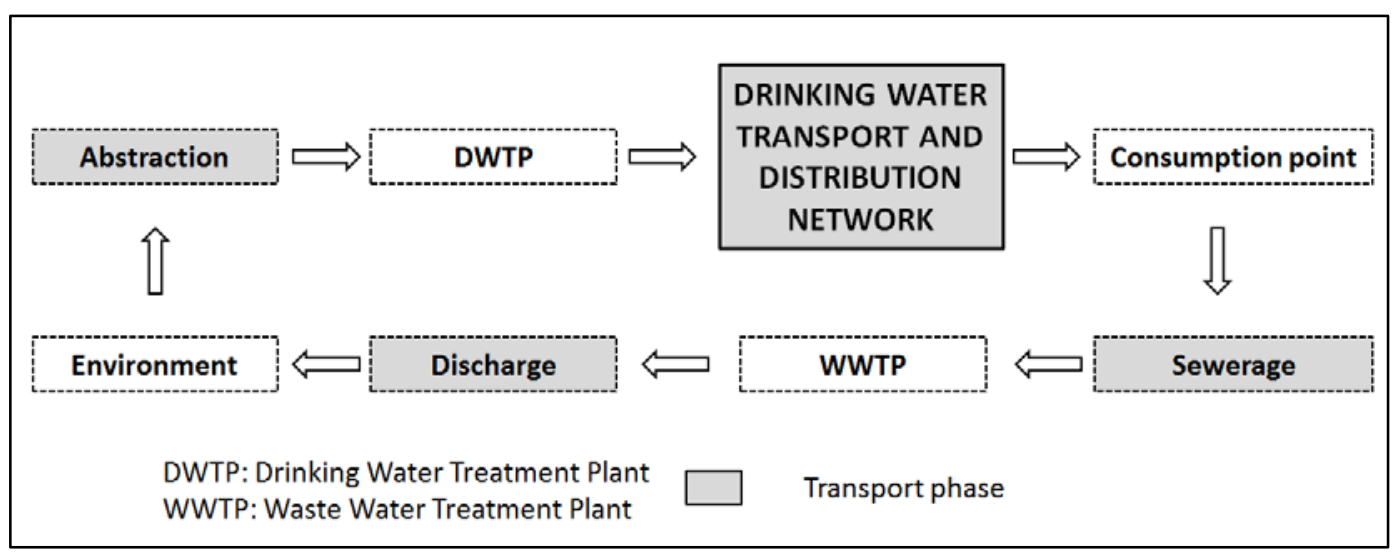

Figure 1. DWTDN within the urban water cycle.

Among the environmental impacts generated by the consumption of water, greenhouse gas (GHG) emissions are of paramount interest. Sharma et al. (2008) analysed the GHG emissions released within the construction and operation of the UWC infrastructures in a residential area of 86,000 inhabitants, which generated 16,000 to $24,000 \mathrm{t}$ of $\mathrm{CO}_{2}$ eq./year. A similar study by Friedrich et al. (2009) for 200,000 residents obtained values of 6,000 to 10,000 t of $\mathrm{CO}_{2}$ eq./year. Another study, by Muñoz et al. (2010), for a broader area presented emissions of 1.5 to $2.5 \mathrm{t}$ of $\mathrm{CO}_{2}$ eq. $/ \mathrm{m}^{3}$ of supplied water. The results presented in these articles show the great variability of values and functional units. Therefore, a top-down study comparing a representative sample of cases and providing average values for the consumption of water and energy would be of interest. 
This article focuses on the drinking water transport and distribution network (DWTDN), which includes the transport of drinking water from the DWTP to the consumption point (Figure 1). Similarly to the UWC state of the art, studies focused on this subject present great variability, although they have shown that the reduction of DWTDN-related environmental impacts is of interest. According to the results found in articles that focus on one case study network, the DWTDN can represent between 20 and 40\% of the total UWC impacts (Amores et al., 2013; Lemos et al., 2013). However, a report from Griffiths-Sattenspiel \& Wilson (2009) analysing the UWC energy consumption in the USA (including consumption in households) shows that the environmental impacts of the DWTDN can represent between 3 and 24\% of the energy consumption required to supply water. This study will assess more cases in Europe, providing data for contrast and analysing the factors that generate such a wide range of results.

Moreover, the state of the art of UWC focused on this subject presents a great variability, although it has shown that the reduction of DWTDN environmental impacts is of interest. For example, according to Amores et al. (2013) and Lemos et al. (2013), the DWTDN can represent between 20 and $40 \%$ of the total UWC impacts, while Griffiths-Sattenspiel and Wilson (2009) reported that the environmental impacts of the DWTDN can represent between 3 and 24\% of the energy consumption required to supply water.

\subsection{Drinking water transport and distribution network}

The DWTDN system consists of a series of stages the water has to cover, from the first water storage tank just after the drinking water treatment plant (DWTP) to the consumption point. Its life cycle can be divided in two main blocks: construction (production, transport, installation and end of life) and operation (use and maintenance) (Figure 2). The factors influencing the environmental impacts of the construction phase can be determined and generalised for all networks. The most relevant factors are the length of the network, the pipe material used and the dimensions of the trench for installation (Sanjuan-Delmás et al., 2013). In contrast, the use phase depends on factors whose influence is not as clear, such as the geographical location of the network elements, the urban form and the economic activity in the area. This results in large variations among the resource consumption of different networks. It must also be highlighted that the cost of the energy for pumping water is not significant compared with other expenses, such as the cost of the soil. In order to address this great variability of the use phase, it was decided that it should be analysed separately. For this reason, the use phase of the DWTDN was excluded from Sanjuan-Delmás et al. (2013). The present article aims to deal with this phase only.

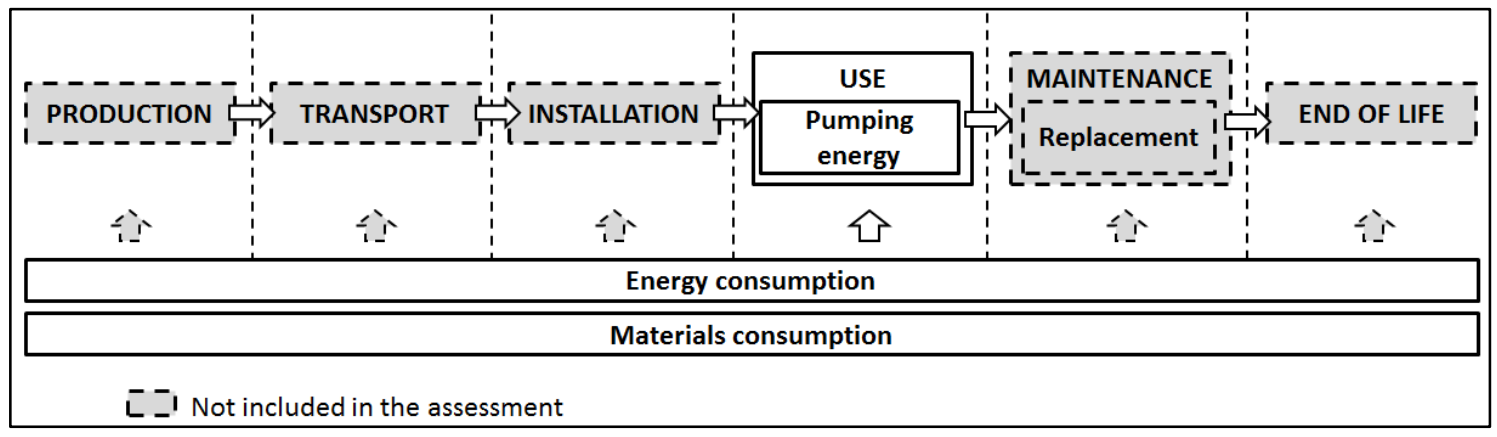


The maintenance phase includes operations such as internal coating of the pipes, rehabilitation, replacement of smaller parts of a pipeline, repair and inspection. The environmental impact these operations generate is relevant when the grid is stagnant, because there is no impact of DWTDN construction (Venkatesh \& Brattebø, 2012). Nevertheless, previous studies have concluded that the resource consumption of the maintenance phase is negligible compared with the energy consumed to pump water (Venkatesh \& Brattebø, 2011; Piratla et al, 2012; Del Borghi et al, 2013). For this reason, the maintenance phase was not considered in this study.

This article aims to address the environmental impacts of the use stage, and thus, the remaining elements of the DWTDN life cycle were excluded from the scope of the study.

Figure 3 shows a diagram of the DWTDN and the boundaries of the system under study. After the DWTP, water reaches the first tank and is then distributed through the transport network until the secondary tanks. Then, it is delivered to the consumption points through the distribution network. Pumping can be required both in the transport and the distribution network and water loss can take place in both networks. The section considered in the study starts at the exit of the first water tank, until the consumption point. The presence of flow meters at the beginning and end of this section allows the measurement of the water flow.

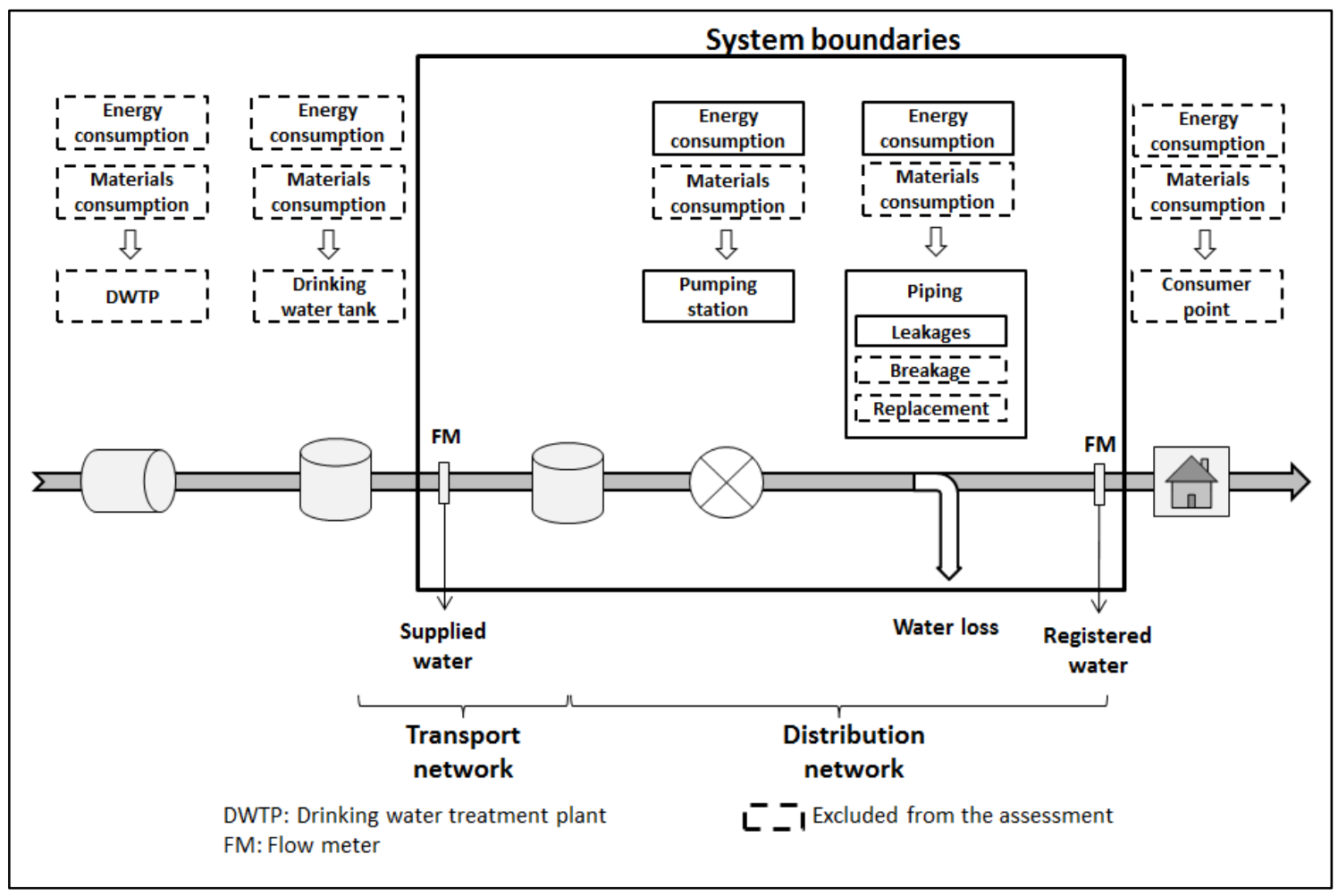

Figure 3 Diagram of the DWTDN with the system boundaries of the study.

Previous literature has analysed the whole UWC altogether obtaining general results. The use phase can account for a large percentage of the UWC energy consumption (60 to $91 \%$; Stokes \& Horvath, 2006). The most characteristic feature of this phase is 
the electricity consumption required to pump water through the DWTDN. Previous results have presented a large variation and represent a significant part of the environmental impacts, for example, $17.2 \%$ of the UWC energy consumption (Venkatesh \& Brattebø, 2011) and 98\% of the DWTDN environmental impacts (Piratla et al., 2012). Moreover, the environmental impacts derived from water pumping have a great potential for reduction by, for instance, increasing the share of renewable energies in the electricity mix (Mohapatra, 2002). This study aims to provide further information about the use phase of the DWTDN and the variability of results observed in previous studies, through the assessment of data from 50 real cases.

The energy consumption for pumping water has a strong relation with urban planning (Filion, 2008) as well as with orography and the sequence of urban structure development. The greater the difference in height or the longer the distance between the consumption point and the DWTP, the greater the increase in energy needed to pump water. The same is true for the form of urban planning and the initial estimations made. Thus, this energy consumption will differ from one municipality to another depending on the location of the elements of the network in the territory and their adaptation along time. Another factor to take into account is that this energy for pumping increases with the aging of the network due to increased roughness of the pipe (Filion et al., 2004) and factors such as more frequent leakages.

If the orography of the area allows it, the transport of water through the DWTDN can be accomplished by gravity, without, or with relatively little, energy consumption. When this is not possible, the use of more sustainable energy sources to generate the electricity required to pump the water may help reduce the environmental impacts of the DWTDN. For instance, the main contribution to the environmental impacts of the DWTDN in the city of Alexandria was the generation of electricity with fossil fuels (Mahgoub et al., 2010).

Finally, one important issue regarding the environmental impacts of the DWTDN is the loss of water through the network by leakages (Friedrich et al., 2009). Losing water increases the environmental impacts of the water supply system because, on the one hand, it increases the volume of water treated and the energy consumed to transport it and, on the other hand, because of the loss of resources. In Europe, there are great differences in the percentage of water lost through the urban water cycle, varying from less than 5\% (Germany) to 50\% (Bulgaria). For Spain, approximately $20 \%$ of the water is lost (European Environmental Agency, 2003). Although these are estimates, it is clear that there is great potential for the reduction of water consumption by reducing the amount of water lost.

Having observed the high variability of use phase environmental impacts in previous literature and the lack of global data about the use phase; this study aims to assess the relevant variables that influence the environmental impacts of the DWTDN use phase by means of the assessment of a representative sample of 50 municipalities. The specific objectives are:

- To obtain average data for the electricity and water consumption of the DWTDN use phase for a representative sample of 50 municipalities. 
- To identify other variables influencing the environmental impacts of the DWTDN use phase.

- To contrast the environmental impacts of the cases in the sample with results from case studies in previous literature.

- To assess the main factors affecting the environmental impacts of the DWTDN.

\section{Materials and methods}

\subsection{Sample of municipalities and variables}

The use phase of the DWTDN was assessed through a statistical analysis based on data from 50 Spanish municipalities for the year 2011. These data were provided by Agbar (2013) through its databases CONTEC (CONTEC (C, 2012) and GISAgua (GISAgua (C), 2012). Because all the data come from the same database, the methodology for their collection is consistent for the entire sample. All data utilised regarding the 50 municipalities are detailed in Supplementary table $\mathrm{A}$.

In terms of size, the range of municipalities included in the sample is within the most common in Spain. Indeed, small to medium-sized municipalities (smaller than 50,000 inhabitants) represent more than $98 \%$ of Spanish towns (INE, 2011). The municipalities belong to the two major climates in Spain according to the Köppen classification system: Mediterranean (the vast majority of the Spanish territory) and Oceanic (north and north-west).

Table 1 shows the variables considered in the statistical analysis. Non-registered water is considered an approximation of water loss. However, this variable includes other components. As seen in Table 2, apparent losses, customer metering inaccuracies and unmetered consumption are also included in the non-registered water. The relative variables included in the statistical analysis have been divided by the inhabitants supplied by the network in each municipality, the length of the network $(\mathrm{km})$ or the cubic meters of water registered at households.

Table 1. Explanation of the variables and the clusters in the statistical assessment

\begin{tabular}{|c|c|c|}
\hline Variable* & Unit & Explanation \\
\hline $\begin{array}{l}\text { Inhabitants } \\
\text { supplied }\end{array}$ & Number & Number of permanent inhabitants supplied in the municipality. \\
\hline $\begin{array}{l}\text { Length of the } \\
\text { transport network }\end{array}$ & $\mathrm{km}$ & $\begin{array}{l}\text { Length of network from the first water storage tank after the DWTDN to } \\
\text { the water storage tank prior to the distribution network (see Figure } 3 \text { ). }\end{array}$ \\
\hline $\begin{array}{l}\text { Length of the } \\
\text { distribution network }\end{array}$ & $\mathrm{km}$ & $\begin{array}{l}\text { Length of the network from the water storage tank after the transport } \\
\text { network to the households (see Figure 3). }\end{array}$ \\
\hline Population density & $\begin{array}{l}\text { Inhabitant/ } \\
\mathrm{km}^{2}\end{array}$ & $\begin{array}{l}\text { Number of inhabitants supplied over the total area within the legal limits } \\
\text { of the municipality }\left(\mathrm{km}^{2}\right) \text {. }\end{array}$ \\
\hline Seasonality & - & $\begin{array}{l}\text { Population of the municipality supplied in peaks over the population } \\
\text { permanently supplied (absolute number). }\end{array}$ \\
\hline $\begin{array}{l}\text { Electricity } \\
\text { consumption }\end{array}$ & kWh/year & $\begin{array}{l}\text { Electricity required to pump water supplied through the network (total per } \\
\text { municipality). }\end{array}$ \\
\hline $\mathrm{CO}_{2}$ emissions & $\mathrm{kg} \mathrm{CO} 2$ & $\begin{array}{l}\text { GHG emissions derived from producing the electricity required for the } \\
\text { transport of water. }\end{array}$ \\
\hline Water supplied & $\mathrm{m}^{3} /$ year & $\begin{array}{l}\text { Quantity of water metered at the exit of the water tank located after the } \\
\text { DWTP (see Figure 3). }\end{array}$ \\
\hline
\end{tabular}




\begin{tabular}{|c|c|l|}
\hline Water registered & $\mathrm{m}^{3} / \mathrm{year}$ & $\begin{array}{l}\text { Quantity of water measured by the flow meters installed in the } \\
\text { households of the municipality. }\end{array}$ \\
\hline $\begin{array}{l}\text { Non-registered } \\
\text { water supplied }\end{array}$ & $\mathrm{m}^{3} / \mathrm{year}$ & Water supplied minus water registered. \\
\hline
\end{tabular}

DWTP= drinking water treatment plant

*All these variables are for 2011

Table 2. International Water Association standard water balance

\begin{tabular}{|c|c|c|}
\hline \multirow{4}{*}{$\begin{array}{c}\text { System } \\
\text { input volume }\end{array}$} & \multirow{2}{*}{$\begin{array}{c}\text { Authorised } \\
\text { consumption }\end{array}$} & $\begin{array}{ll}\text { Billed authorised consumption: } \\
\text { - } \\
\text { - } \quad \text { Unmetered } \\
\end{array}$ \\
\hline & & $\begin{array}{l}\text { Unbilled authorised consumption: } \\
\text { - } \quad \text { Metered } \\
\text { - } \quad \text { Unmetered }\end{array}$ \\
\hline & \multirow{2}{*}{ Water losses } & $\begin{array}{l}\text { Apparent losses: } \\
\text { - Unauthorised consumption } \\
\text { - } \quad \text { Customer metering inaccuracies }\end{array}$ \\
\hline & & $\begin{array}{l}\text { Real losses: } \\
\text { - Leakages (network, tanks and connections) } \\
\text { - Overflow (tanks) }\end{array}$ \\
\hline
\end{tabular}

Source: Adapted from (IWA, 2003)

\subsection{Comparison of the statistical parameters by clusters}

To evaluate which factors have an influence on the environmental impacts of the DWTDN, a preliminary selection was done. Population size, seasonality, population density, climate, location and gross income per capita were selected for the assessment. For each of these factors, the sample was grouped according to the criteria stated in Table 3 , and the resulting clusters were analysed through its summary statistics (mean, standard error) for relative variables of interest.

Regarding population size, the distinction between small and large municipalities varies depending on the country and the specific area. In Spain, previous literature shows that the number of inhabitants considered for the grouping of cases varies depending on the goal and scope of the study. In this paper, municipalities below 10,000 inhabitants (small) and between 10,000 and 50,000 inhabitants (medium) were considered. The same limits were used for a social study in Goerlich \& Mas (2004) and Díaz (2006).

The variations in the population and, thus, in the amount of water delivered over the year will have an impact on the network usage and ageing. For instance, pressure fluctuations could occur because of the changes in the amount of water extracted from the network due to variations in the number of consumers, which might increase breakages. Seasonality has been defined as inhabitants supplied in peaks over permanent inhabitants supplied by a network. In Spain, highly touristic municipalities are expected to be seasonal because their populations increase substantially during summer. To group the sample in clusters, the median (1.2) was established as the limit between seasonal and non-seasonal.

The effect of population density on the environmental impacts is unclear because although the distance to be covered is longer when the population density is low, higher pressures are needed to pump water to the top of buildings when the population 
density is high. Additionally, less densely populated areas usually show higher water consumption per inhabitant due to the higher amounts of water consumed in private gardens and swimming pools (Saurí and Cantó, 2008). In this case, the median (90 inhabitants $/ \mathrm{km}^{2}$ ) was considered as the limit between high and low density populations.

Additionally, 2 qualitative factors were included in the assessment: the climate (Mediterranean and Oceanic) and the location (coastal or inland).

To compare the means, t-tests were conducted by adjusting the $p$ value with the Bonferroni correction. Levene's test was conducted, and homogeneity of the variance was not assumed when positive $(<0.05)$. These methods are commonly used and accepted in statistics. For graphical representations, in order to better represent relations between variables, scatter plots were used for the representation of continuous variables (size, population density and seasonality), and box plots were used for nominal variables (location and climate).

\subsection{Environmental impacts}

The environmental impacts were considered through the GHG emissions derived from the electricity consumption of the network use phase. The emissions were calculated using the software Simapro 7.3 (PRé Consultants, 2010) and the calculation method CML 2 baseline 2000 (Guinée et al. 2001) for the global warming potential impact category. The environmental information from Ecoinvent 2.2 (Ecoinvent, 2009) was used, adapting the Spanish electricity mix for 2011 (IEA, 2014).

\subsection{Correlation between variables and regression models}

Pearson correlations between the variables considered (Table 1) were calculated. When values were higher than 0.3 , the variables were considered to hold a certain correlation between them.

Based on the results obtained for the correlations, regression models were defined with the main variables influencing the environmental impacts of the DWTDN as dependent variables. The significance was tested through one-way ANOVA, which is a commonly used method.

To validate the models, each equation was applied by utilising data from the cases of the sample. The estimations obtained were compared with the real values, and the resulting errors were calculated. 


\section{Results and discussion}

\subsection{Clusters by size, location, climate, density, seasonality and income per capita}

Table 3 shows a comparison of the mean values and the standard errors obtained by grouping the data into clusters for relative variables that were considered relevant for the environmental impacts of the network. The criteria for the aggrupation of the cases were stated in section 3.2.

The results show that size, location and density might have an influence on the relative electricity consumption of the DWTDN, because the means of their clusters are significantly different. Similarly, seasonality would have some influence on the registered water consumption per inhabitant. Despite not being statistically significant, the mean values of climate clusters present great differences for the relative electricity consumption, and their assessment can also be of interest.

To see the relations between clusters showing significant differences more clearly, they were represented graphically. The resulting graphs are shown in Figure 4.

Regarding the clusters by size, it can be observed that small municipalities have nearly 14 times higher average electricity consumption than medium-sized municipalities, which indicates that population size most likely has an influence on the electricity consumption of the network. The scatter plot in Figure 4 shows that all medium municipalities (from 10,000 to 50,000 inhabitants) have an annual value below 3.79E-3 $\mathrm{kWh} / \mathrm{m}^{3}$ of registered water $\mathrm{km}$ of network. In contrast, small municipalities present a much wider range of values, with the mean value being 3 times higher than that medium municipalities. This might indicate that the relative consumption tends towards a narrower range of values, which is altered in small-sized towns by case-specific factors. These factors would lose relevance in medium municipalities due to the larger quantity of water demanded, which dilutes these alterations. Additionally, higher energy consumptions in smaller municipalities might be explained by a scale economy effect; a higher number of inhabitants would then imply a relatively more efficient use of resources.

Towns with a low population density present a relative electricity consumption 7 times higher than towns with a high population density. The scatter plot in Figure 4 shows that all the municipalities with high consumptions have relatively low population densities. Note that cases above $1 \mathrm{E}-1 \mathrm{kWh} / \mathrm{m}^{3} \cdot \mathrm{km}$ are the same as those observed in the number of inhabitants-relative electricity consumption scatter plot. This is because population density holds a certain correlation with the number of inhabitants (Table 4), meaning that within the sample, larger towns are usually more densely populated.

On the one hand, higher electricity requirements in less densely populated cases might be attributed to the necessity of covering longer distances. On the other hand, more densely populated areas also need extra energy to pump the water to the tops of buildings. Judging by the results, it appears that the first statement has greater relevance than the second. Additionally, in low density towns, the location of buildings within the topography could have a greater effect on the overall electricity consumption, which can result in larger electricity consumption values. 
Table 3. Summary statistics for the sample of small to medium municipalities by cluster for 2011

\begin{tabular}{|c|c|c|c|c|c|c|c|}
\hline & & & $\mathbf{N}$ & $\begin{array}{c}\text { Electricity } \\
\text { consumption (kWh/ } \\
\mathrm{m}^{3} \text { registered water- } \\
\text { km of network }^{1} \text { ) }\end{array}$ & 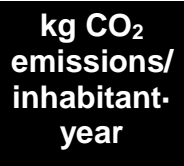 & $\begin{array}{c}\text { Registered } \\
\text { water } \\
\text { (m²/inhabitant) }\end{array}$ & $\begin{array}{c}\text { Non-registered } \\
\text { water }\left(\mathrm{m}^{3} / \mathrm{m}^{3} \text { of }\right. \\
\text { water registered) }\end{array}$ \\
\hline \multirow{4}{*}{ Size } & \multirow{2}{*}{$\begin{array}{c}\text { Small }(<10,000 \\
\text { inhabitants) }\end{array}$} & $\mu$ & \multirow{2}{*}{31} & $1.15 \mathrm{E}-02^{\star \star}$ & 7.47E+00 & $7.65 E+01$ & 7.30E-01 \\
\hline & & SEM & & $2.70 \mathrm{E}-03$ & $2.21 \mathrm{E}+00$ & $7.90 \mathrm{E}+00$ & $6.80 E-02$ \\
\hline & \multirow{2}{*}{$\begin{array}{c}\text { Medium } \\
(10,000-50,000 \\
\text { inhabitants })\end{array}$} & $\mu$ & \multirow{2}{*}{19} & $8.30 \mathrm{E}-04^{\star \star}$ & $2.37 \mathrm{E}+00$ & $6.96 \mathrm{E}+01$ & 6.35E-01 \\
\hline & & SEM & & 2.44E-04 & $6.25 E-01$ & $5.08 \mathrm{E}+00$ & 7.16E-02 \\
\hline \multirow{4}{*}{ Seasonality } & \multirow{2}{*}{ Low $(\leq 1.2)$} & $\mu$ & \multirow{2}{*}{24} & 4.12E-03 & $3.19 \mathrm{E}+00$ & $6.19 \mathrm{E}+01^{*}$ & 6.77E-01 \\
\hline & & SEM & & $1.32 \mathrm{E}-03$ & 6.89E-01 & $3.71 \mathrm{E}+00$ & $5.28 E-02$ \\
\hline & \multirow{2}{*}{ High (> 1.2) } & $\mu$ & \multirow{2}{*}{26} & 1.05E-02 & $7.69 \mathrm{E}+00$ & $8.50 \mathrm{E}+01^{*}$ & 7.10E-01 \\
\hline & & SEM & & $3.21 \mathrm{E}-03$ & $2.62 \mathrm{E}+00$ & $9.04 \mathrm{E}+00$ & 8.41E-02 \\
\hline \multirow{4}{*}{$\begin{array}{l}\text { Population } \\
\text { density }\end{array}$} & \multirow{2}{*}{$\begin{array}{c}\text { Low }(<90 \\
\left.\text { inhabitants } / \mathrm{km}^{2}\right)\end{array}$} & $\mu$ & \multirow{2}{*}{25} & $1.31 \mathrm{E}-02^{\star *}$ & $8.28 E+00$ & $7.78 \mathrm{E}+01$ & 7.67E-01 \\
\hline & & SEM & & $3.24 \mathrm{E}-03$ & $2.66 \mathrm{E}+00$ & $9.65 \mathrm{E}+00$ & 7.87E-02 \\
\hline & \multirow{2}{*}{$\begin{array}{c}\text { High }(\geq 90 \\
\left.\text { inhabitants } / \mathrm{km}^{2}\right)\end{array}$} & $\mu$ & \multirow{2}{*}{25} & $1.79 \mathrm{E}-03^{\star \star}$ & $2.78 \mathrm{E}+00$ & $7.00 \mathrm{E}+01$ & $6.21 E-01$ \\
\hline & & SEM & & $6.41 E-04$ & 7.66E-01 & $4.23 E+00$ & 6.01E-02 \\
\hline \multirow{4}{*}{ Climate } & \multirow{2}{*}{ Mediterranean } & $\mu$ & \multirow{2}{*}{46} & 8.00E-03 & $5.75 \mathrm{E}+00$ & $7.25 \mathrm{E}+01$ & 7.07E-01 \\
\hline & & SEM & & $1.96 \mathrm{E}-03$ & $1.54 \mathrm{E}+00$ & $4.90 \mathrm{E}+00$ & 5.38E-02 \\
\hline & \multirow{2}{*}{ Oceanic } & $\mu$ & \multirow{2}{*}{4} & 1.16E-03 & $3.00 E+00$ & $9.03 E+01$ & 5.50E-01 \\
\hline & & SEM & & $7.25 E-04$ & $1.23 \mathrm{E}+00$ & $3.71 \mathrm{E}+01$ & $7.15 E-02$ \\
\hline \multirow{4}{*}{ Location } & \multirow{2}{*}{ Coast } & $\mu$ & \multirow{2}{*}{10} & $1.32 \mathrm{E}-03^{\star *}$ & $2.94 \mathrm{E}+00$ & $1.05 E+02$ & 7.58E-01 \\
\hline & & SEM & & 5.86E-04 & 7.34E-01 & $2.08 \mathrm{E}+01$ & 1.37E-01 \\
\hline & \multirow{2}{*}{ Inland } & $\mu$ & \multirow{2}{*}{40} & $8.99 \mathrm{E}-03^{\star \star}$ & $6.18 \mathrm{E}+00$ & $6.61 \mathrm{E}+01$ & $6.78 \mathrm{E}-01$ \\
\hline & & SEM & & $2.22 \mathrm{E}-03$ & $1.76 \mathrm{E}+00$ & $3.23 E+00$ & 5.31E-02 \\
\hline \multirow{4}{*}{$\begin{array}{c}\text { Gross } \\
\text { income per } \\
\text { capita }^{2}\end{array}$} & \multirow{2}{*}{ Low } & $\mu$ & \multirow{2}{*}{19} & $1.16 \mathrm{E}-02$ & $8.16 \mathrm{E}+00$ & $7.38 \mathrm{E}+01$ & 7.33E-01 \\
\hline & & SEM & & 4.07E-03 & $3.47 \mathrm{E}+00$ & $1.05 \mathrm{E}+01$ & 8.83E-02 \\
\hline & \multirow{2}{*}{ High } & $\mu$ & \multirow{2}{*}{21} & 4.28E-03 & $4.22 \mathrm{E}+00$ & $7.30 \mathrm{E}+01$ & 7.31E-01 \\
\hline & & SEM & & $1.94 \mathrm{E}-03$ & $1.17 \mathrm{E}+00$ & $5.09 E+00$ & 8.06E-02 \\
\hline \multirow{4}{*}{\multicolumn{2}{|c|}{ All cases }} & $\mu$ & & $7.45 \mathrm{E}-03$ & $5.53 E+00$ & $7.39 \mathrm{E}+01$ & 6.94E-01 \\
\hline & & SEM & & $1.83 \mathrm{E}-03$ & $1.42 \mathrm{E}+00$ & $5.24 \mathrm{E}+00$ & 5.01E-02 \\
\hline & & Min. & 50 & 3.70E-06 & 5.00E-03 & $3.90 \mathrm{E}+01$ & 1.30E-01 \\
\hline & & Max. & & 7.39E-02 & $6.78 \mathrm{E}+01$ & $2.45 \mathrm{E}+02$ & $1.63 \mathrm{E}+00$ \\
\hline
\end{tabular}

${ }^{*}$ p value $<0.05,{ }^{* \star}$ p value $<0.01$

${ }^{1}$ distribution network, ${ }^{2}$ value not available for $20 \%$ of the municipalities, $\mu=$ mean, SEM= standard error of the mean, Min.=Minimum, Max.=Maximum

For a hypothetical network $20 \mathrm{~km}$ in length, the average electricity consumption for water distribution would represent 3 and $33 \%$ of the energy consumption of drinking water with reverse osmosis and ultrafiltration as treatments, respectively (data for the treatment plant retrieved from Vince et al., 2008; pumping not considered). Considering the data from the treatment plant analysed in Racoviceanu et al. (2007), the electricity consumption for water distribution would reach $50 \%$ (not considering pumping within the treatment plant). This shows that the distribution of water can account for a significant percentage of the water supply electricity consumption. 
No significant differences were observed regarding the water demand, although previous literature has proved that higher consumptions occur with less densely populated areas (Saurí and Cantó, 2008). This relation might have been found if smaller areas of clearly low and high population densities were analysed instead of the average value of the municipality, given that a municipality can be heterogeneously distributed along the territory.

The clusters by location show that although inland municipalities have, on average, higher electricity consumption than coastal municipalities (nearly 7 times higher), their mean values (Figure 4) do not show clear differences. The coastal cluster presents a much lower dispersion, most likely due to the relatively smaller number of cases (10 coastal, 40 inland). Thus, the assessment of a large sample would clarify whether this difference is truly significant. One main explanation for these lower consumptions in coastal municipalities would be a more common application of gravity for the transport of water, which would reduce the need for electricity to transport water. Additionally, coastal towns are usually settled in flatter locations (frequently in alluvial plains), and thus, less energy is required to pump the water to the households.

Similarly, the Mediterranean climate municipalities show a relative electricity consumption nearly 7 times higher than that of the Oceanic municipalities. This could be explained by the higher availability of water in Atlantic areas, which would allow the supply of water from more accessible places. However, the box plot in Figure 4 also shows that the clusters' medians are similar in this case. The Oceanic cluster has a smaller dispersion, most likely due to the lower number of cases (4 Oceanic, 46 Mediterranean). The assessment of a greater number of municipalities with an Oceanic climate would again allow the confirmation or dismissal the differences observed.

The average GHG emissions derived from the network electricity consumption (5.53 $\mathrm{kg} / \mathrm{inhabitant}$ year) would represent between 2 and $3 \%$ of the UWC emissions in the case study in Sharma et al. (2008) and between 11 and $18 \%$ of the case study in Friedrich et al. (2009). These percentages are reasonably consistent with the range of values found in other studies analysing the whole UWC. Venkatesh \& Brattebø (2011) found that water pumping represented $17 \%$ of the UWC energy consumption. Lemos et al. (2013) and Amores et al. (2013) found higher percentages for the contribution of the supply network to the environmental impacts of the UWC (between 20 and 40\%), which can partially be explained because these studies also included the network infrastructure. However, considering the lowest and highest values found in the sample, the resulting percentages of the UWC GHG emissions for the prior case studies might vary from less than $1 \%$ to more than twice the UWC emissions.

Thus, the differences among the results found in previous literature are consistent with the values observed in this study and are due to the wide range of electricity consumptions that can be found for different cases. Apart from the variables under study, which might affect the electricity consumption, there is an inherent variability due to the specific conditions of each case. As stated in section 1.2, apart from the location of the elements within the territory, urban planning also influences the energy consumption of the network (Filion et al., 2004; 2008) as well as its development along time. 
A 50\% higher water consumption value was found for seasonal municipalities (those with a large difference between the population supplied in peaks and permanently supplied) compared with the non-seasonal municipalities. This might be due to the presence of more water demanding activities in more seasonal municipalities linked with tourism. The scatter plot in Figure 4 shows that most of the cases with a seasonality value above 1.3 hold higher water consumptions. Additionally, when the 10 cases farther from the regression line are excluded, the main cloud shows a certain linear relation between the two variables considered $\left(R^{2}=0.45\right)$. Therefore, there is weak evidence of a link between water consumption and seasonality. Further studies on the issue might clarify this relation.

The rest of the clusters analysed do not show significant differences in the water registered per inhabitant. This shows that the water demand might not be affected by the variables considered (population size, seasonality, population density, climate, location and gross income per capita). Indeed, the water consumption in dwellings and other facilities depends mostly on its residents' decisions rather than on the characteristics of the municipality where they are located. Nevertheless, some public policies can encourage water savings among the population in areas suffering from drought. In this case, Mediterranean and Oceanic climates present nearly equal water consumptions, although the Mediterranean areas are prone to drought.

For non-registered water, no significant differences were found for any of the factors assessed. As stated in section 3.1, non-registered water can be affected by different elements, such as inaccuracies in the flow metering and illegal connections to the network. Thus, although there might be differences between the clusters regarding the water loss, these differences would be diluted. In fact, the average value for $\mathrm{m}^{3}$ of nonregistered $/ \mathrm{m}^{3}$ of registered water is approximately 0.7 , which means the water loss should be approximately $40 \%$. This result contrasts with other values found in the literature that indicate a $20 \%$ loss for Spanish municipalities (European Environmental Agency, 2003). Therefore, there is every likelihood that other factors, such as unmetered consumption, influence non-registered water (Table 2). 
Figure 4. Scatter and box plots representing the relative electricity consumption in relation to the number of inhabitants supplied, population density, climate and location variables

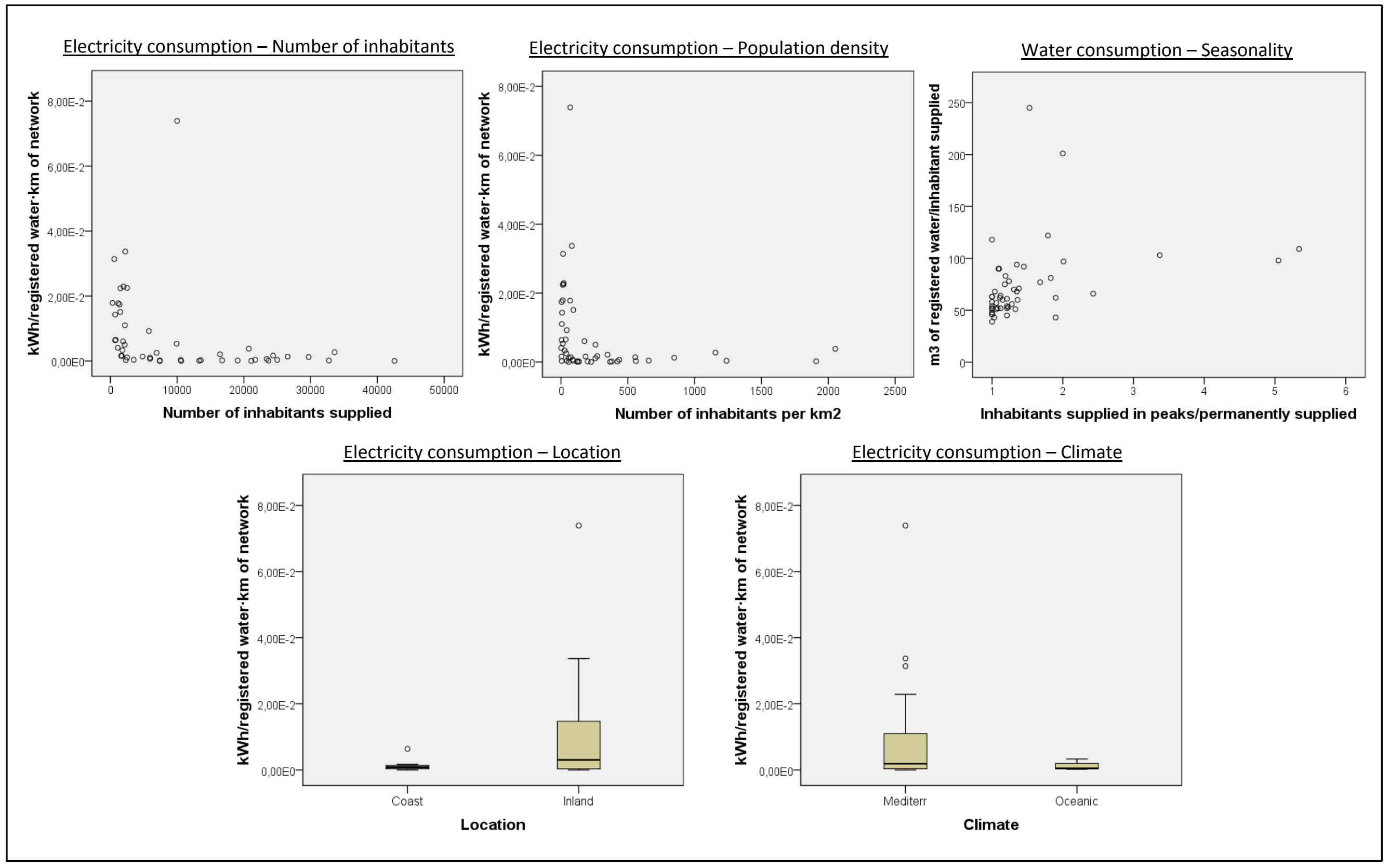




\subsection{Correlations between variables}

Table 4 shows the correlations between the variables included in the study.

The results show that the amount of registered water is highly correlated with population density (0.57). However, as stated in section 4.1, population density is also related to the number of inhabitants (larger cities are usually more densely populated). Thus, the correlation with registered water would only mean that more densely populated municipalities tend to be larger and have greater demands. Indeed, it can be observed that population density also has a certain correlation with the number of inhabitants supplied.

Regarding the length of the network, two different variables were considered: the transport length and the distribution network length (see Figure 3 and section 3.1). The distribution network shows a high correlation with the number of inhabitants, which is logical because this network carries water to households, and thus, many divisions will be required to reach the streets of municipalities. A similar correlation can be observed between the distribution network and the water registered. This is due to the high correlation between the number of inhabitants and the registered water (0.91) stated above.

In contrast, the transport network does not show significant correlations with any of the variables considered, with the registered water or with the population supplied. This length depends, in fact, on the location of the municipality in relation to the DWTP because its function is to transport water from this plant to the distribution network. Hence, this lack of correlation can be considered reasonable.

It can be observed that electricity consumption is not correlated with the number of inhabitants supplied or with the length of the network. This means that larger populations (with larger networks) do not necessarily have greater electricity demands, even though they do have larger networks and greater water consumptions. As seen in section 4.1, small and less densely populated municipalities tend to present a wide range of relative electricity consumptions due to their specific circumstances, usually linked with the location of the elements of the network in the territory, thus justifying this general lack of correlation.

No significant correlations were found for seasonality, non-registered water and gross income per capita. The correlation between non-registered water and other variables can be explained by its high correlation with registered water. Apart from that, these variables would not be influenced by any of the others included in the study. 
Table 4. Pearson correlation for the variables in the statistical assessment

\begin{tabular}{|c|c|c|c|c|c|c|c|c|}
\hline & 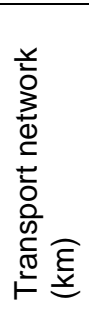 & 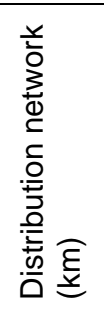 & 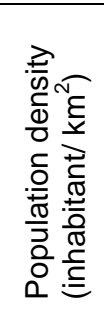 & 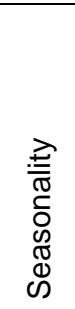 & 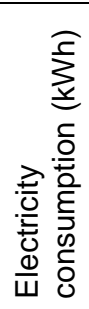 & 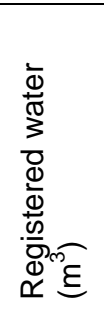 & 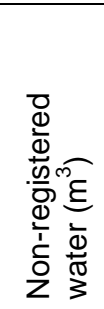 & 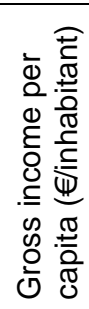 \\
\hline Inhabitants supplied & -.01 & $.73 * *$ & $.50 * *$ & .20 & .27 & $.91 * *$ & $.81^{* *}$ & $.37 *$ \\
\hline $\begin{array}{l}\text { Transport network } \\
(\mathrm{km})\end{array}$ & & .10 & -.15 & -.01 & .04 & .01 & .03 & -.21 \\
\hline $\begin{array}{l}\text { Distribution network } \\
(\mathrm{km})\end{array}$ & & & $.38^{* *}$ & .22 & .11 & $.77^{* *}$ & $.66 * *$ & $.33^{*}$ \\
\hline $\begin{array}{l}\text { Population density } \\
\text { (inhabitant } / \mathrm{km}^{2} \text { ) }\end{array}$ & & & & .10 & .17 & $.57^{* *}$ & $.61^{* *}$ & $.45 * *$ \\
\hline Seasonality & & & & & .24 & $.45^{* *}$ & .25 & .20 \\
\hline $\begin{array}{l}\text { Electricity } \\
\text { consumption (kWh) }\end{array}$ & & & & & & .25 & $.33^{*}$ & .09 \\
\hline $\begin{array}{l}\text { Registered water } \\
\left(\mathrm{m}^{3}\right)\end{array}$ & & & & & & & $.86 * *$ & $.48^{* *}$ \\
\hline $\begin{array}{l}\text { Non-registered } \\
\text { water }\left(\mathrm{m}^{3}\right)\end{array}$ & & & & & & & & $.56^{* *}$ \\
\hline
\end{tabular}

${ }^{*} \mathrm{p}<0.05 .{ }^{* *} \mathrm{p}<0.01$

Coloured-shaded cells indicate significant correlation: light grey $(0.3 \leq|r| \leq 0.5)$. dark grey $(0.5<|r| \leq 0.65)$. black $(|r|>0.65)$

\subsection{Regression models}

This section presents regression models for the prediction of registered water $\left(\mathrm{m}^{3}\right)$, the length of the distribution network $(\mathrm{km})$ and electricity consumption $(\mathrm{kWh})$ based on the results of the previous section. These are relevant variables that influence the environmental impacts of the DWTDN.

Registered water is highly correlated with the number of inhabitants, which is an easily accessible value in any municipality. For this reason, a regression model, linear in this case, was defined for the prediction of registered water (RW), with the number of inhabitants (NI) as the independent variable (1).

$\mathrm{RW}=67.1\left[\mathrm{~m}^{3}\right] \cdot \mathrm{NI}$

The overall model is significant $(p<0.01)$, and the coefficient of determination $\left(R^{2}\right)$ is 0.82 . The regression line was forced to cross the $(0.0)$ coordinates because the constant was not significant ( $p>0.05$ ) and to improve accuracy.

For the estimation of the distribution network length $(\mathrm{km}$; $\mathrm{LN})$, two possible variables could be used for being highly correlated with the prior: number of inhabitants (NI) and registered water $\left(\mathrm{m}^{3} ; \mathrm{RW}\right)$. Two models were created, one with each of these variables $(2 ; 3)$.

$\mathrm{LN}=5.73 \mathrm{E}-3[\mathrm{~km} / \mathrm{inhabitants}] \cdot \mathrm{NI}$ 
${ }^{*}$ Cases S, AF and AP were excluded as outliers

Both models are significant $(p<0.01)$ and show a coefficient of determination $\left(R^{2}\right)$ of 0.68 . As seen in model 1 , the regression line in models 2 and 3 was forced to cross the (0.0) coordinates because none of the constants were significant.

Regarding the electricity consumption, as stated in section 3.2, a direct correlation was not found for any of the variables considered. The relation between the relative electricity consumption ( $\mathrm{kWh} / \mathrm{m}^{3}$ of registered water. $\mathrm{km}$ of network) and the number of inhabitants supplied (represented in Figure 4) was used to provide a model for the prediction of the electricity consumption. A power curve regression model was defined with the relative electricity consumption (REC) as the dependent variable and the inhabitants (NI) supplied as the independent variable (4) (Figure 5).

$\mathrm{REC}=12.7\left[\mathrm{kWh} / \mathrm{m}^{3} \cdot \mathrm{km}\right] \cdot \mathrm{NI}^{-1.064} \quad(4)^{\star \star}$

${ }^{*}$ Case $\mathrm{AE}$ was excluded as an outlier

The model is significant, as is the coefficient $(p<0.01)$. A coefficient of determination $\left(R^{2}\right)$ of 0.41 was reached. To predict the electricity consumption (EC), these results must be multiplied by the length of the network $(\mathrm{LN} ; \mathrm{km})$ and the registered water (RW;

$\mathrm{m}^{3}$ ) (5). These two variables can be replaced by the previously stated equations 1 and 2 , resulting in one unique model with the number of inhabitants as the only independent variable (6).

$\mathrm{EC}=12.7\left[\mathrm{kWh} / \mathrm{m}^{3} \cdot \mathrm{km}\right] \cdot \mathrm{NI}^{-1.064} \cdot \mathrm{RW} \cdot \mathrm{LN} \quad(5)^{\star \star}$

$\mathrm{EC}=12.7\left[\mathrm{kWh} / \mathrm{m}^{3} \cdot \mathrm{km}\right] \cdot \mathrm{NI}^{-1.064} \cdot 67.1\left[\mathrm{~m}^{3}\right] \cdot \mathrm{NI} \cdot 5.73 \mathrm{E}-3[\mathrm{~km} /$ inhabitants $] \cdot \mathrm{NI}$

$(6)^{\star \star}$ 
Figure 5. Representation of the power curve estimation model for the relative electricity consumption prediction

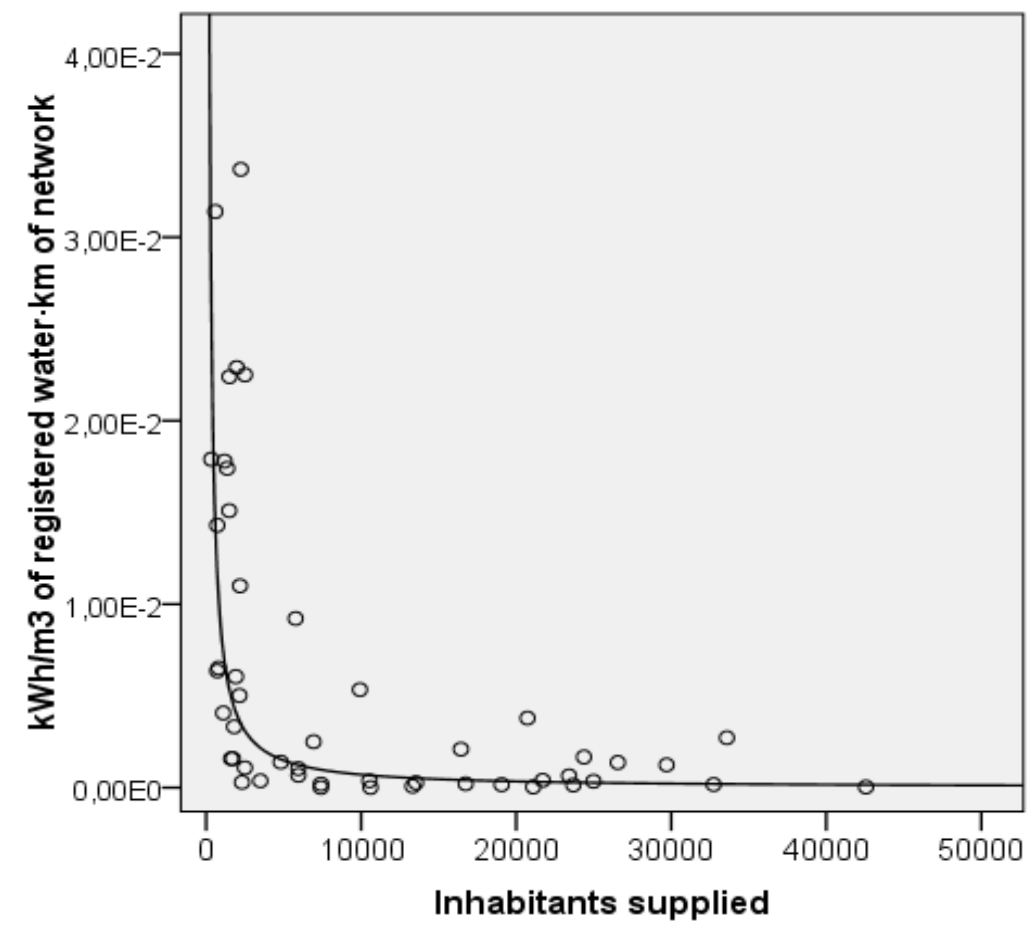

\subsection{Validation of the models}

To assess the accuracy of the models proposed in section 4.3, a model validation was conducted using the original data from the cases under study (section 3.3; Supplementary table A). The results of the validation are shown in Table 5.

It can be observed that for model 1 (prediction of water demand), the error is below $50 \%$ for $90 \%$ of the cases included in the sample. The validation of models 2 and 3 (prediction of the network length) resulted in approximately $60 \%$ of the cases having an error below $50 \%$ and nearly all the cases having an error below $90 \%$.

Models 4 and 6 present significantly higher errors. Only 20 and 30\% of the cases, respectively, show an error below $50 \%$. For both models, an error below $70 \%$ was found for $40 \%$ of the cases, and an error below $90 \%$ was found for $70 \%$ of the cases. This shows that these models might be useful to obtain a rough estimation of the value, but its accuracy is limited. Estimations resulting in values higher than 7.4E-2 $\mathrm{kWh} / \mathrm{m}^{3} \cdot \mathrm{km}$ or $1.8 \mathrm{E} 6 \mathrm{kWh}$ for small municipalities and $3.8 \mathrm{E}-3 \mathrm{kWh} / \mathrm{m}^{3} \cdot \mathrm{km}$ or $8.9 \mathrm{E} 5$ $\mathrm{kWh}$ for medium municipalities should not be considered valid, because such values have not been observed in the sample under assessment. 
Table 5. Results of the validation of models 1 to 6 .

\begin{tabular}{|c|c|c|c|c|c|c|}
\multicolumn{1}{c|}{} & \multicolumn{2}{c|}{ Error $<\mathbf{5 0 \%}$} & \multicolumn{2}{c|}{ Error < $\mathbf{7 0 \%}$} & \multicolumn{2}{c|}{ Error < 90\% } \\
\cline { 2 - 7 } & $\mathbf{N}$ & $\mathbf{\%}$ & $\mathbf{N}$ & $\mathbf{\%}$ & $\mathbf{N}$ & $\mathbf{\%}$ \\
\hline Model 1 & 45 & 90 & 48 & 96 & 50 & 100 \\
\hline Model 2 & 28 & 56 & 40 & 80 & 47 & 94 \\
\hline Model 3 & 29 & 58 & 43 & 86 & 47 & 94 \\
\hline Model 4 & 10 & 20 & 18 & 36 & 33 & 66 \\
\hline Model 6 & 16 & 32 & 22 & 44 & 36 & 72 \\
\hline
\end{tabular}

Electricity is a more difficult element to measure than water, and the measurement errors can be greater, which can lead to higher differences among the cases. Moreover, electricity can present a wider range of values, including municipalities transporting water by gravity with nearly zero consumption. These characteristics make modelling electricity consumption difficult.

To facilitate future statistical studies for the provision of more accurate data and models, a protocol for data collection in water supply networks should be implemented by organisations managing the water supply. This protocol should include all the variables considered in the study as well as others potentially affecting the environmental impacts of the network.

A thorough assessment of some case studies might provide more accurate information about the relation between energy consumption and other variables and might be able to successfully model these relations. However, this task falls outside the scope of this study, which aims to make a top-down assessment of and provide general information about drinking water supply networks from a representative sample of cases. 


\section{Conclusions}

This study obtained average values of electricity consumption, GHG emissions and water demand in municipalities below 50,000 inhabitants (e.g., $7.45 \mathrm{E}-3 \mathrm{kWh} / \mathrm{m}^{3}$ registered water. $\mathrm{km}$ of network, $5.53 \mathrm{~kg}$ CO2 emissions/inhabitant-year, 73.9 $\mathrm{m}^{3} /$ inhabitant) for the DWTDN operational phase. These data will be useful in future studies, especially for contrasting the environmental impacts of the supply network operational phase with those of UWC case specific studies or assessments of other UWC stages.

The analysis also provided information about the potential influence of factors such as population size and density on the environmental impacts of the DWTDN operational phase.

Because small municipalities ( $<10,000$ inhabitants) have lower absolute water and energy demands, case specific factors affecting their electricity consumption have a greater relative weight. Thus, the size of the municipality can affect its relative electricity consumption, which is bound to be higher in small compared with medium municipalities $(10,000-50,000$ inhabitants). In the sample, small municipalities present values, on average, nearly 14 times larger than those of medium municipalities (1.15E2 as opposed to $8.3 \mathrm{E}-4 \mathrm{kWh} / \mathrm{m}^{3}$ registered water $\cdot \mathrm{km}$ of network). A similar relation was found for population density. Due to the relatively longer distances water has to cover, less densely populated municipalities present higher relative electricity consumption (on average, approximately 7 times higher).

The quantity of GHG emissions derived from the electricity consumption of the sample cases are consistent with the values found in previous literature. Although varied, the results from previous articles (Sharma et al., 2008; Friedrich et al., 2009; Venkatesh \& Brattebø, 2011; Lemos et al., 2013; Amores et al., 2013) are within the range of values observed in this study. The differences among these results can be explained by the specificity of each case study; this paper provides average values that can be used in future studies to avoid considering such specific conditions.

Additionally, six models were defined for the prediction of water demand, length of the network and electricity consumption. In contrast with water and length of the network, only a rough approximation was reached with the model for the prediction of electricity consumption $\left(R^{2}=0.41\right)$, because electricity is more difficult to measure and presents a wider range of values. In the future, companies managing water supply should implement a protocol for the collection of data in order to model this variable more accurately.

For location (cost or inland) and climate (Mediterranean or Oceanic) variables, some indications of a relation with electricity consumption were found. Certain differences were observed between the clusters, but the evidence was not strong enough to reach solid conclusions. Similarly, a slight correlation between the seasonality (number of inhabitants supplied in peaks over inhabitants permanently supplied) and water registered variables was found but were not significant enough. These results show tendencies that might be further assessed in future studies. 
Finally, the relation between water loss and other variables should be assessed in a more thorough bottom-up study, as it is believed that external factors stated by IWA (2003), such as un-metered connections, dilute the water losses. 


\section{Acknowledgements}

This research was sponsored by the European LIFE+ programme as part of the AQUAENVEC project "Assessment and improvement of the urban water cycle ecoefficiency use LCA and LCC" on the urban water cycle (LIFE10 ENV/ES/000520).

The authors are grateful for the support of the Spanish Ministry of Education and Science through the project BIA (2010-20789-C04-01).

The authors are also grateful for the support of the Spanish Ministry of Education and Science through the project PLUVISOST (CTM2010-17365). 


\section{Supplementary material}

Supplementary table A can be found in the attached excel file. 


\section{References}

Agbar (C. <http://www.agbar.es/en/home.html> [Accessed on September 2013]

Amores, M. J., Meneses, M., Pasqualino, J., Antón, A., \& Castells, F. (2013).

Environmental assessment of urban water cycle on Mediterranean conditions by

LCA approach. Journal of Cleaner Production, 43, 84-92.

CONTEC, Control Técnico del Ciclo Integral del Agua, 2012 @ Aqualogy Services Company

Del Borghi, A., Strazza, C., Gallo, M., Messineo, S., \& Naso, M. (2013). Water supply and sustainability: life cycle assessment of water collection, treatment and distribution service. The International Journal of Life Cycle Assessment, 18(5), 1158-1168.

Mahgoub, M.E.-S.M., Van der Steen, N.P., Abu-Zeid, K., Vairavamoorthy, K., 2010. Towards sustainability in urban water: a life cycle analysis of the urban water system of Alexandria City, Egypt. Journal of Cleaner Production 18, 1100-1106

Ecoinvent (2009) Swiss Centre for Life Cycle Inventories. Ecoinvent database v3.0. Technical report. http://www.ecoinvent.ch/ Accessed March 2014.

European Environmental Agency. (2003). (WQ06) Water use efficiency (in cities): leakage. [PDF Document] <http://www.eea.europa.eu/data-andmaps/indicators/water-use-efficiency-in-cities-leakage/water-use-efficiency-incities-leakage/at_download/file>

Filion, Y. R., MacLean, H. L., \& Karney, B. W. (2004). Life-cycle energy analysis of a water distribution system. Journal of Infrastructure Systems, 10(3), 120-130.

Filion, Y. R. (2008). Impact of urban form on energy use in water distribution systems. Journal of Infrastructure Systems, 14(4), 337-346.

Friedrich, E., Pillay, S., \& Buckley, C. A. (2009). Carbon footprint analysis for increasing water supply and sanitation in South Africa: a case study. Journal of Cleaner Production, 17(1), 1-12.

GISAgua. 2012. ( ) Aqualogy Services Company

Goerlich, F. J., \& Mas, M. (2004). Distribución personal de la renta en España. 19732001.

Griffiths-sattenspiel, B. \& Wilson, W. (2009). The Carbon Footprint of Water. A River Network Report. [PDF Document]

$<$ http://www.csu.edu/cerc/researchreports/documents/CarbonFootprintofWaterRiverNetwork-2009.pdf $>$

Guinée, J.B. (ed), et al. (2001) Life cycle assessment: an operational guide to the ISO standards. Parts 1 and 2. Ministry of Housing, Spatial Planning and Environment 
(VROM) and Centre of Environmental Science (CML), Den Haag (Guinée JB, final editor)

Instituto Nacional de Estadística. (2011). Cifras de población y censos demográficos. $<$ http://www.ine.es/inebmenu/mnu_cifraspob.htm>

Institute of Water Association. (2003) The IWA water loss task force. Water 21 Article No 2 Assessing Non-Revenue Water and its Components: A Practical Approach. [PDF Document] $<$ http://www.studiomarcofantozzi.it/Water\%2021\%20\%20Article\%20No.\%202\%20-\%20Assessing\%20NRW.pdf>

International Energy Agency (IEA). $<$ http://www.iea.org/statistics/statisticssearch/report/?\&country=SPAIN\&year=201 1\&product=ElectricityandHeat> [Accessed on March 2014]

Kennedy, C., Pincetl, S., \& Bunje, P. (2011). The study of urban metabolism and its applications to urban planning and design. Environmental pollution, 159(8), 19651973.

Lemos, D.; Dias, A. C.; Gabarrell, X. \& Arroja. L. (2013). Environmental assessment of an urban water system. Journal of Cleaner Production. doi:10.1016/j.jclepro.2013.04.029

Mohapatra, P., Siebel, M., Gijzen, H., Van der Hoek, J., \& Groot, C. (2002). Improving eco-efficiency of Amsterdam water supply: A LCA approach. Aqua, 51, 217-227.

Muñoz, I., Milà-i-Canals, L., \& Fernández-Alba, A. R. (2010). Life cycle assessment of water supply plans in Mediterranean Spain. Journal of Industrial Ecology, 14(6), 902-918.

Díaz, A. P. (2006). Los pequeños municipios ante los retos del desarrollo. Norba. Revista de geografía, (11), 183-197.

Piratla, K. R.; Asce, S. M.; Ariaratnam, S. T.; Asce, M. \& Cohen. A. (2012). Estimation of CO 2 Emissions from the Life Cycle of a Potable Water Pipeline Project. Journal of Managing in Engineering 2012.28:22-30. doi:10.1061/(ASCE)ME.1943-5479.0000069.

Sanjuan-Delmás, D. et al.. Environmental assessment of different pipelines for drinking water transport and distribution network in small to medium cities: a case from Betanzos. Spain. Journal of Cleaner Production (2013). http://dx.doi.org/10.1016/j.jclepro.2013.10.055

Sharma, A. K., Grant, A. L., Grant, T., Pamminger, F., \& Opray, L. (2008). Environmental and economic assessment of urban water services for a greenfield development. Environmental Engineering Science, 26(5), 921-934.

Stokes, J. \& Horvath, A. (2006). Life Cycle Energy Assessment of Alternative Water Supply Systems. International Journal of LCA. 11(5). 335-343. 
UNESCO. J. Marsalek, B.E. Jiménez-Cisneros, P.-A. Malmquist, M. Karamouz, J. Goldenfum \& B. Chocat (2006). Urban water cycle processes and interactions. International hydrological programme. [PDF Document] $<$ http://www.bvsde.paho.org/bvsacd/cd63/149460E.pdf >

Venkatesh, G., \& Brattebø, H. (2011). Energy consumption, costs and environmental impacts for urban water cycle services: Case study of Oslo (Norway). Energy, 36(2), 792-800.

Venkatesh, G., \& Brattebø, H. (2012). Assessment of environmental impacts of an aging and stagnating water supply pipeline network. Journal of Industrial Ecology, 16(5), $722-734$. 